\title{
A Case of Asymptomatic Cardiopericardial Hydatid Cyst
}

\author{
Aytekin Guven, ${ }^{1}$ MD, Gulizar SoKmen,,${ }^{1}$ MD, Murvet YuKSEL,${ }^{2}$ MD, \\ Omer Faruk KoKoglu, ${ }^{3} \mathrm{MD}$, Nurhan KoKSAL, ${ }^{4} \mathrm{MD}$, and Ali CetinKaYA, ${ }^{5} \mathrm{MD}$
}

\begin{abstract}
SUMMARY
Cases with cardiac hydatid cyst disease are uncommon, being approximately $0.2-2 \%$ of all cases. Most cardiac hydatid cysts are located in the interventricular septum or left ventricular wall. Pericardial location is very rare. We report a 42 -year old Turkish man with pericardial hydatid cyst disease who was otherwise asymptomatic, having no cardiac symptomatology. The most appropriate therapeutical option for a hydatid cyst is surgical removal of the cyst mass. However, our patient refused surgical treatment and thus medical treatment with albendazole was initiated. Following the first month of the drug therapy, pericardial effusion disappeared. The cystic nature of the mass disappeared and was solidified at the $6^{\text {th }}$ month of treatment. The patient has been followed-up by us asymptomatically. (Jpn Heart J 2004; 45: 541-545)
\end{abstract}

Key words: Cardiac cyst, Pericardial cyst, Albendazole therapy

HUMAN hydatid disease caused by Echinococcus granulosus is of worldwide importance and presents medical, veterinary, and economic problems in developing countries. Echinococcal disease is endemic to sheepherding regions of the world, and it affects the heart in fewer than $2 \%$ of patients infected by the parasite. $^{1)}$

Herein we describe an unusual echocardiographic appearance of an echinococcal lesion attached to the left ventricular apex of an asymptomatic patient.

\section{CASE REPORT}

A 42 year old male patient visited a chest disease clinic due to symptoms of respiratory infection and was referred to our clinic due to an increased cardiothoracic ratio on chest roentgenogram. The patient did not suffer from any cardiovascular complaint in his medical history. On physical examination, his

From the Departments of ${ }^{1}$ Cardiology, ${ }^{2}$ Radiology, ${ }^{3}$ Clinical Microbiology and Infectious Diseases, ${ }^{4}$ Pulmonary Disease, and ${ }^{5}$ Internal Medicine, School of Medicine, Kahramanmaras Sutcu Imam University, Kahramanmaras, Turkey.

Address for correspondence: Aytekin Guven, MD, Department of Cardiology, School of Medicine, Kahramanmaras Sutcu Imam University, 46050 Kahramanmaras, Turkey.

Received for publication July 8, 2003.

Revised and accepted December 4, 2003. 
blood pressure was $130 / 80 \mathrm{mmHg}$ and his pulse was $82 / \mathrm{min}$ and regular. Other findings of physical examination, including a cardiovascular examination, were normal. On complete blood count, hemoglobin was $13.4 \mathrm{~g} / \mathrm{dL}$, hematocrit was $37.8 \%$, white blood cell count was $7600 / \mathrm{dL}$, and eosinophil ratio was found $12 \%$. The erythrocyte sedimentation rate was 22 /hour. Biochemical analysis revealed normal results. Electrocardiogram was normal. There was no other abnormality on chest X-rays apart from an increased cardiothoracic ratio. Echocardiographic (Acuson model Aspen, Acuson Computer Sonography, Mountain View, California) examination detected a regularly contoured cystic mass attached to the left ventricular apex in the intrapericardial cavity together with minimal pericardial effusion around cystic muss (Figure 1). All other echocardiographic findings were normal. The indirect hemagglutination inhibition test for echinococcus was positive in 1/1600 titers. The serum IgE level was 650 units/L (range 0-150 units/ L). On spiral computed tomography (CT), a cystic mass in accordance with a hydatid cyst $(33.3 \times 43.6 \mathrm{~mm})$ was found attached to the left ventricular apex in the pericardial cavity (Figure 2). The results of respiratory function test, abdominal USG, and lung and cranial CT were all normal.

Although the patient was asymptomatic, he was given albendazole therapy due to the potential risks and complications of a hydatid cyst. The albendazole therapy consisted of three cycles of $400 \mathrm{mg}$ twice a day for 4 weeks, followed by a 2-week rest period without therapy, because of its greater absorption from the gastrointestinal tract and higher plasma levels.

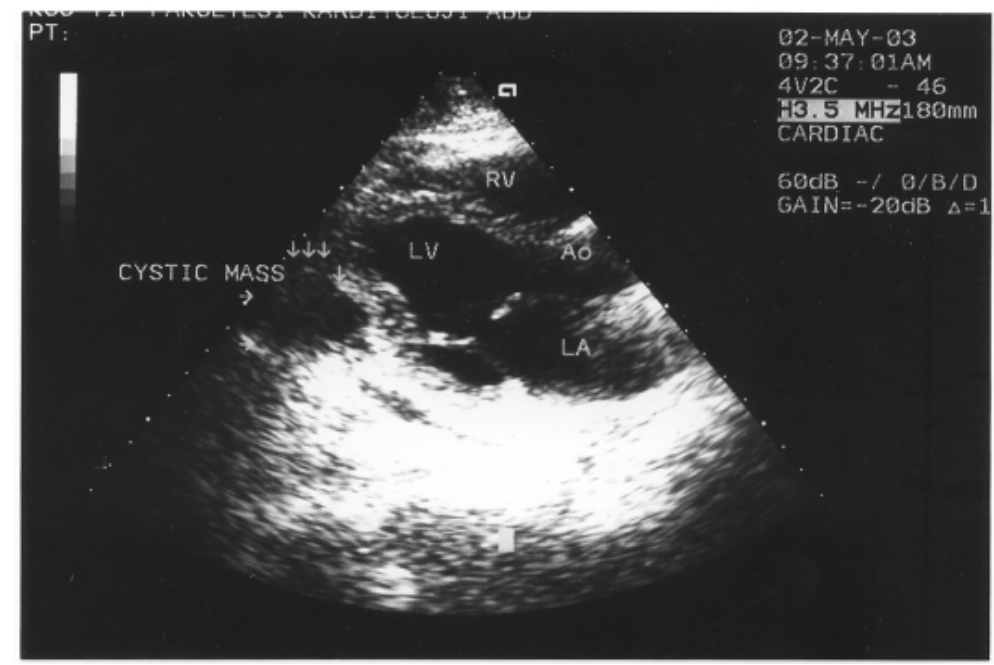

Figure 1. Transthoracic two-dimensional echocardiogram of parasternal long-axis view showing a cystic mass in the pericardial cavity. 


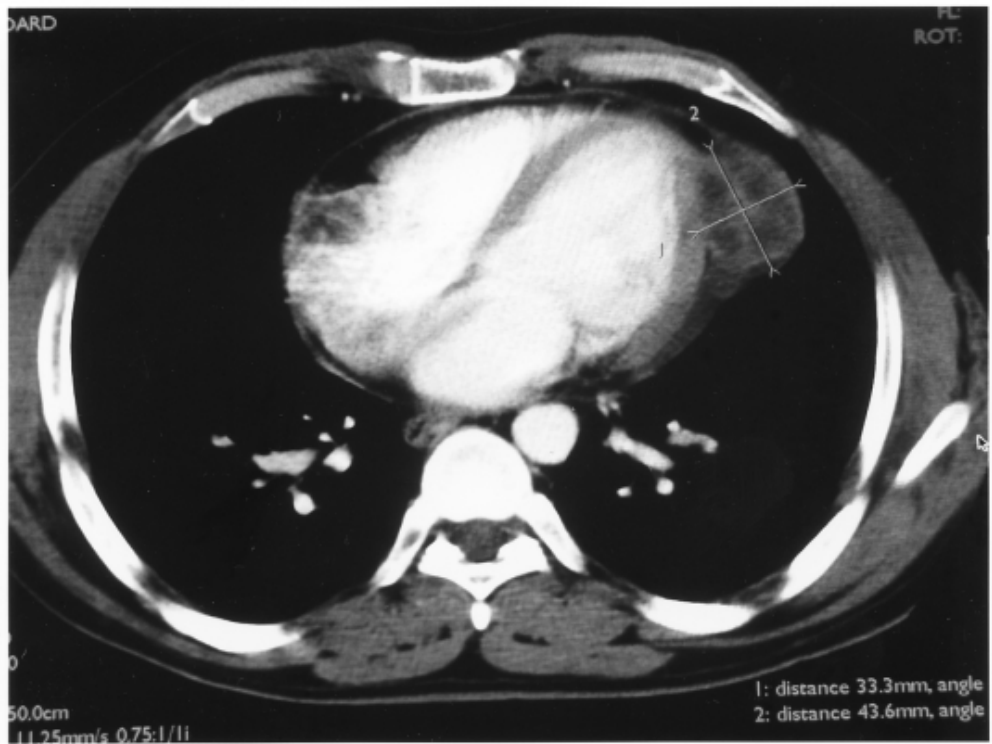

Figure 2. Thorax CT scan with contrast enhanced demonstrated pericardial hydatid cyst with multiple septations in close proximity to the left ventricle.

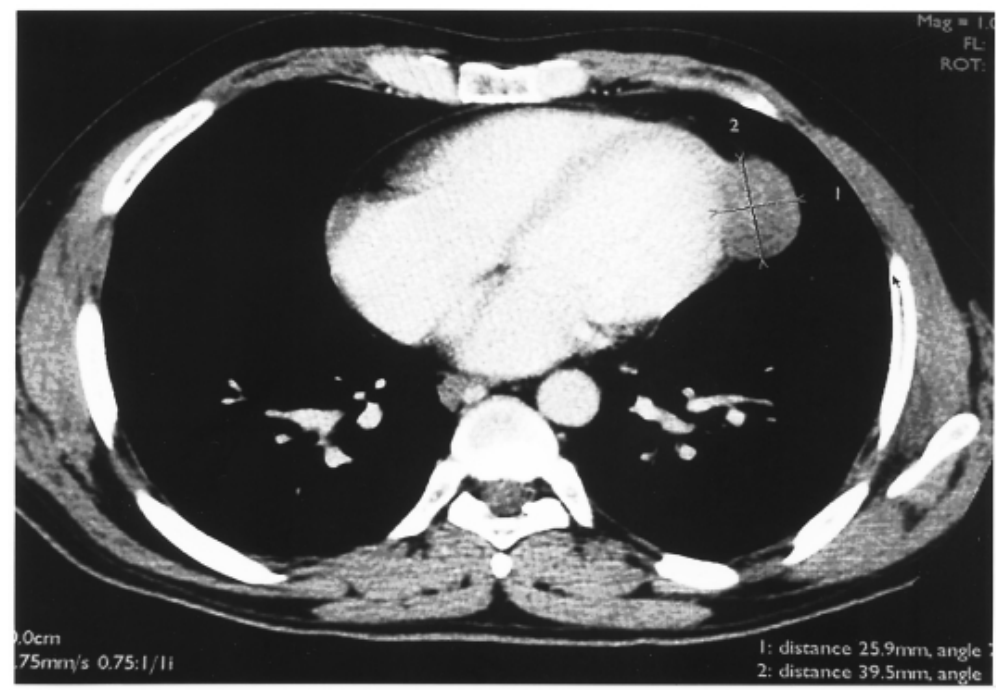

Figure 3. Following six months of treatment, the mass decreased in size and its cystic nature was replaced by solidification.

Control echocardiography, which was performed one month after the drug therapy, revealed the pericardial effusion around the cystic mass had disappeared. A control CT of the case after six months of treatment showed that the mass had decreased in size $(25.9 \times 39.5 \mathrm{~mm})$ and solidified (Figure 3$)$. Since it takes a long 
time for a cystic mass to get smaller and disappear, we are continuing medical treatment and follow-up at our outpatient clinic. There have not been any complications.

\section{DiscUSSION}

Humans become infected during accidental ingestion of food or water contaminated by tapeworm eggs. After the eggs are ingested, they pass into the small bowel, where they hatch and are absorbed. Next, the parasites travel through the bloodstream and eventually establish cystic lesions in various organs. The liver is the most likely organ to be involved through portal drainage, but any organ may be infected. Each cystic lesion contains fluid and multiple secondary daughter cysts. ${ }^{2,3)}$ Our patient was not a stockbreeder and he has no pets in his house. Contamination by a hydatid cyst might be due to the widespread consumption of giblets (edible visceral organs of birds) in our region of Turkey.

The heart is rarely involved in echinococcal disease. Cysts may reach the heart through the lymphatic system or by escaping the liver and lung filters during primary infection. The myocardium becomes involved when the cysts travel through the heart and reach the myocardium by the coronary circulation.

The distribution of cardiac echinococcosis parallels that of coronary blood flow, and most lesions $(60 \%)$ occur within the left ventricle. Fifteen percent of lesions affect the right ventricle, and $15 \%$ affect the ventricular septum. Atrial involvement is rare. Two to $10 \%$ of cysts occur in the pericardium. ${ }^{4}$

Clinical presentation of a cardiac hydatid cyst varies widely and its diagnosis is very difficult. As well as being small and solitary, cardiac cysts may remain asymptomatic for many years. When they are huge or exist in large numbers, they may lead to symptoms and signs similar to the mass of a cardiac tumor. They may cause many cardiac events such as angina pectoris, palpitations, and arrhythmias. ${ }^{5)}$ A cyst localized in the intrapericardial cavity may cause pericarditis and/ or cardiac tamponade. ${ }^{6}$ Anaphylactic reactions may develop in some patients due to the antigenic properties of cystic fluid. In this patient, there was minimal effusion around the cyst and it disappeared following the albendazole therapy. There were no signs and symptoms indicating pericarditis in our patient.

The best treatment method for a cardiac hydatid cyst is surgical interventions. ${ }^{7}$ However, because our patient was asymptomatic, he refused to have an operation. Thus, albendazole therapy was given to the patient. We found favorable results in similar cases administered albendazole in the literature. ${ }^{8,9)}$ In our case, the size of the cyst was unchanged after the first month of therapy. But the reactive pericardial effusion disappeared. After almost six months, the cyst had decreased in size and solidified on control CT. This indicated that the cyst also 
became radiologically inactive following the albendazole treatment. ${ }^{10)}$ It is recommended that albendazole treatment be given to the patient for at least one year. Our patient has been taking albendazole and is being followed-up by our clinic regularly.

\section{REFERENCES}

1. Todorov T, Vutova K, Mechkov G, et al. Experience in the chemotherapy of severe, inoperable echinococcosis in man. Infection 1992; 20: 19-24.

2. Krogstad DJ. Echinococcal disease. Curr Clin Top Infect Dis 1991; 11: 52-60.

3. Ameli M, Mobarhan HA, Nouraii SS. Surgical treatment of hydatid cysts of the heart: report of six cases. J Thorac Cardiovasc Surg 1989; 98: 892-901.

4. Limacher MC, McEntee CW, Attar M, Nelson JG, DeBakey ME, Quinones MA. Cardiac echinococcal cyst: diagnosis by two-dimensional echocardiography. J Am Coll Cardiol 1983; 2: 574-7.

5. Yalcin E, Dogru D, Ozcelik U, Kiper N, Gocmen A, Akhan A. Cardiac hydatid cyst and pulmonary hydatidosis in a child. Pediatric Infect Dis J 2002; 21: 1178-80.

6. Pinch LW, Sehat A. Constrictive pericarditis associated with echinococcus cyst. Chest 1972; 61: 194-5.

7. Snodgross D, Blame S. Cardiac hydatid disease: report of two cases. Australas Radiol 2002; 46: 194-6.

8. Kardaras F, Kardara D, Tselikos D, et al. Fifteen year surveillance of echinococcal heart disease from a referral hospital in Greece. Eur Heart J 1996; 17: 1265-70.

9. Steiger U, Cotting J, Reichen J. Albendazole treatment of echinococcosis in humans: effect of microsomal metabolism and drug tolerance. Clin Pharmacol Ther 1990; 47: 347-53.

10. Liu Y, Wang X, Wu J. Continuous long-term therapy in intraabdominal cystic echinococcosis. Chin Med J 2000; 113: 827-32. 